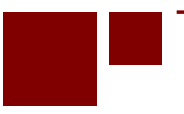

C E N T E R for RETIREMENT RES E A R C H at BOSTON COLLEGE

\title{
THE BEHAVIORAL AND CONSUMPTION EFFECTS OF SOCIAL SECURITY CHANGES
}

\author{
Wenliang Hou and Geoffrey T. Sanzenbacher
}

CRR WP 2017-10

September 2017

\author{
Center for Retirement Research at Boston College \\ Hovey House \\ 140 Commonwealth Avenue \\ Chestnut Hill, MA 02467
}

Tel: 617-552-1762 Fax: 617-552-0191

http://crr.bc.edu

Both authors are with the Center for Retirement Research at Boston College. Wenliang Hou is a senior research advisor and Geoffrey T. Sanzenbacher is a research economist. The research reported herein was performed pursuant to a grant from the U.S. Social Security Administration (SSA) funded as part of the Retirement Research Consortium. The opinions and conclusions expressed are solely those of the authors and do not represent the opinions or policy of SSA, any agency of the federal government, or Boston College. Neither the United States Government nor any agency thereof, nor any of their employees, makes any warranty, express or implied, or assumes any legal liability or responsibility for the accuracy, completeness, or usefulness of the contents of this report. Reference herein to any specific commercial product, process or service by trade name, trademark, manufacturer, or otherwise does not necessarily constitute or imply endorsement, recommendation or favoring by the United States Government or any agency thereof.

(C) 2017, Wenliang Hou and Geoffrey T. Sanzenbacher. All rights reserved. Short sections of text, not to exceed two paragraphs, may be quoted without explicit permission provided that full credit, including $(\subset$ notice, is given to the source. 


\begin{abstract}
About the Center for Retirement Research
The Center for Retirement Research at Boston College, part of a consortium that includes parallel centers at the University of Michigan and the National Bureau of Economic Research, was established in 1998 through a grant from the Social Security Administration. The Center's mission is to produce first-class research and forge a strong link between the academic community and decision-makers in the public and private sectors around an issue of critical importance to the nation's future. To achieve this mission, the Center sponsors a wide variety of research projects, transmits new findings to a broad audience, trains new scholars, and broadens access to valuable data sources.
\end{abstract}

Center for Retirement Research at Boston College

Hovey House

140 Commonwealth Ave

Chestnut Hill, MA 02467

Tel: 617-552-1762 Fax: 617-552-0191

http://crr.bc.edu

Affiliated Institutions:

The Brookings Institution

Syracuse University

Urban Institute 


\begin{abstract}
Social Security's Trust Fund is projected to be exhausted in 2034. A variety of changes to the program have been put forward that would either push this date out into the future or delay it indefinitely. Some of these changes would cut benefits - e.g., increasing the Full Retirement Age (FRA) to 69 - while others would increase program revenue - e.g., increasing the payroll tax. While Social Security's Office of the Chief Actuary projects the financial impact on the program of a wide variety of changes, understanding the impact of these changes on recipients' behavior and well-being is also a valuable exercise. This paper uses the Gustman and Steinmeier structural model to analyze the effects of four changes to the Social Security program on recipients' retirement timing and household consumption.
\end{abstract}

This paper found that:

- The two policies that reduce benefits - an increase in the FRA to 69 and a reduction in the COLA of 0.5 percentage points - would increase the length of workers' careers by delaying retirement.

- The two policies that increase revenues - an increase in the payroll tax to 7.75 percent and an increase in the cap to cover 90 percent of earnings - would have a negligible impact on retirement timing.

- For the benefit-based policies, the reduction in consumption relative to current policy is relatively high post-retirement, with the COLA adjustment having an increasing effect with time.

- Policies that increase revenue have little effect on consumption after retirement but have a consistent effect during the working life.

The policy implications of this paper are:

- Policymakers can expect individuals to delay retirement more in response to Social Security changes that reduce benefits than from changes that increase revenue.

- In terms of consumption, policymakers considering benefit cuts versus revenue increases face a tradeoff: a sharper reduction in consumption over the shorter span of retirement or a smaller, but more prolonged, reduction in consumption during the working life. 


\section{Introduction}

According to the 2017 Trustees Report, Social Security’s Trust Fund is projected to be exhausted in 2034. Some proposed changes to the Social Security program designed to push this date back would cut benefits - e.g., increasing the Full Retirement Age (FRA) to 69 - while others would increase revenue - e.g., raising the payroll tax. While Social Security's Office of the Chief Actuary projects the financial impact on the program of a wide variety of changes, understanding the impact on recipients' behavior and well-being is also a valuable exercise. This paper examines the effect of four policy changes on the retirement timing and consumption of workers across the income distribution.

The issue with projecting these behavioral effects is that, in many cases, the policies are completely untried. For example, one policy change that has been suggested (and that this paper will examine) is a reduction in the Cost-of-Living Adjustment (COLA). This change would effectively reduce the real benefit by an increasing amount as people age. To date, this type of benefit reduction - one that gets larger with age post-claiming - has not been attempted, so its behavioral impacts and effect on consumption in retirement are largely unknown.

In the absence of a natural experiment, one tool economists use to predict the effect of counter-factual policies is structural modeling. In structural models, the preference parameters that govern individuals’ choices are estimated by observing their behavior given their constraints. For example, in the context of retirement timing, if individuals with few assets retire early when they become ill, then the model would estimate that the disutility from working while ill is so high that people are willing to tolerate lower consumption in retirement. Once this kind of preference is estimated, the econometrician can change the environment - e.g., by making workers healthier - and see how workers' behavior is likely to respond.

This paper uses one particular structural model, from Gustman and Steinmeier (2006), to analyze the effects of four changes to Social Security on recipients' retirement timing and household consumption. All four changes, which include two benefit reductions and two revenue increases, would reduce the financial shortfall by roughly 1 percent of payroll (depending on how they are phased in). ${ }^{1}$ The specific changes are: 1) an increase in the FRA from 67 to 69 with a Delayed Retirement Credit (DRC) available until age 70; 2) a decrease in

\footnotetext{
${ }^{1}$ For simplicity, the policies simulated in this paper are assumed to be implemented in one shot. In reality, the financial impact of most changes to the Social Security program assumes a more gradual phase in.
} 
the COLA of 0.5 percentage points; 3) an increase in the employee portion of the payroll tax from 6.2 percent to 7.75 percent; and 4) an increase in the taxable maximum to cover 90 percent of earnings (roughly \$270,000 in 2016 dollars). The first two policies, which both reduce benefits, would be expected to lead to delayed retirement as workers try to balance the disutility from continued work with the need to make up for a reduced Social Security benefit. The second two policies, which both increase program revenue by reducing pre-retirement income, would be expected to have two offsetting effects: 1) they could speed up retirement as the benefits of continued work are lower; but 2) they could delay retirement to the extent that less is saved at younger ages due to the higher taxes and so extended work is needed to maintain consumption in retirement.

The results confirm this general intuition, although the effect of increasing revenue on retirement timing seems negligible. With respect to increasing the FRA to 69 or reducing the COLA, the effects are a 3.9-percent and a 2.5-percent reduction respectively in the share of individuals completely retired at 69 (the model assumes all individuals claim at 70 at the latest). The increase in the payroll tax raises the share completely retired by just 0.3 percent at age 69 and increasing the cap has an effect of less than 0.1 percent.

The reduction in consumption also differs across policies and, more so than for the reductions in retirement timing, across people with different incomes. For example, at age 70 the average reduction in consumption under the increase in the FRA (relative to current policy) is 5.6 percent for individuals in the lowest third of the income distribution and 2.2 percent for those in the top third. The corresponding numbers for the COLA adjustment are 2.8 percent and 0.8 percent. However, the effect of the COLA adjustment increases with age so that, for those living to age 90 , the reductions are 10.5 percent and 4.0 percent for the lowest and highest third, respectively. Prior to retirement, the effect of benefit reductions on consumption is estimated to be relatively small. On the other hand, an increase in the payroll tax decreases consumption primarily during the working life - by between 1.3 and 1.5 percent between ages 25 and 55 for the lowest third and 1.2 and 1.4 percent for the highest third. The effect during retirement of revenue increases is smaller and operates through reduced savings prior to retirement.

The second section describes the literature on how Social Security policy changes affect retirement timing. The third section reviews the structural model used in this paper and the fourth section describes the data used to estimate the model. The fifth section begins with a discussion 
of the internal and external validity of the model and presents the results of the policy experiments. The final section concludes that the model predicts that benefit reductions tend to have a greater behavioral impact than revenue increases as well as a greater reduction in consumption in retirement. Much of the more muted effect of tax increases is due to the fact that they are spread over a longer period of time.

\section{Literature Review}

The literature on the effects of benefit reductions and revenue increases on retirement timing and consumption are discussed below.

\section{Benefit Reductions}

Increases in the FRA and their effect on retirement timing have been explored extensively in the academic literature. The work most relevant to this paper is done by Gustman and Steinmeier themselves. Gustman and Steinmeier (2006) find that raising the FRA from 65 to 67 increases retirement around the early eligibility age (EEA) and decreases retirement at and after age 65. They argue that the reason for the counterintuitive increase in retirement around the EEA is that the incentive to keep working at these early ages is lower given the benefit reduction (i.e., an additional year of delay yields lower additional income). At and after age 65, the effect is intuitive, with the share completely retired declining by roughly 3 percent. Gustman and Steinmeier (2009) subsequently investigate what share of the increase in labor force participation between 1992 and 2004 was due to changes in Social Security rules over the same period (which include an increase in the FRA) and find they account for about a sixth of the increase. Blau and Goodstein (2010) explore the period since the 1980s and find a larger effect of Social Security rules changes than Gustman and Steinmeier predict. But the rules changes they examine include changes in the DRC in addition to an increase in the FRA. Their finding is that these changes could explain about a quarter to a half of the increase in labor force participation of older men between the late 1980s and the early 2000s. Mastrobuoni (2009) explores the retirement behavior of birth cohorts turning 62 after 2000 and investigates the effect of increases in the FRA specifically. His work suggests that a one-year increase in the FRA would result in a six-month increase in the average age of retirement. 
A decrease in the COLA represents a less explored case, since past changes to the Social Security program have not included this kind of policy. And although a COLA reduction is essentially a real benefit cut, it is a benefit cut with a specific pattern across time - the effect on the benefit is minimal at first but increases with the distance from the time claimed. For example, a COLA cut of 0.5 percentage points will reduce an individual's real Primary Insurance Amount (PIA) by 5 percent after 10 years, 10 percent after 20 years, and 17 percent after 30 years. So while other authors using structural models - notably Gustman and Steinmeier (2006) and Van der Klauuw and Wolpin (2008) - find fairly large effects - on the order of 25 percent in terms of delayed retirement from benefit reductions, it is unclear the results will be as strong for a COLA reduction given that individuals tend to discount the future. It is worth noting that earlier research focused on the effect of benefit increases between 1969 and 1972, for example Burtless (1986), and found that these increases were a minor contributor to an overall speeding up of retirement for the cohorts affected.

The effect on consumption of policies that decrease benefits has received somewhat less attention. Using their structural model, Van der Klauuw and Wolpin (2008) examine these effects for lower-income households and estimate that a reduction in benefits of 25 percent lowers household consumption by a relatively modest amount relative to the benefit decline. On the other hand, researchers have frequently investigated the effects of benefit increases within the context of the lifecycle model. For example, Wilcox (1986) finds that households that experienced a somewhat unexpected increase in benefits (typically informed less than one year but more than one month in advance) saw month-to-month increases in consumption once receiving their benefit, in violation of a simple formulation of the lifecycle model.

\section{Revenue Increases}

Several prior studies have explored the effect of tax increases generally and the payroll tax specifically on retirement timing, but the suggested effect on retirement timing is somewhat unclear. Using a reduced form approach, Alpert and Powell (2012) find that eliminating the employee portion of the FICA tax would reduce retirement for men, although the magnitude of the effect was relatively small at 4 percent. $^{2}$ The structural model of Keane and Wolpin (2008)

\footnotetext{
${ }^{2}$ Schmidt and Sevak (2009) come to a similar conclusion using a reduced form approach, albeit with a slightly larger effect.
} 
agrees with the direction of the effect but predicts a significant and large decrease in labor force participation following an increase in the employee portion of the tax to 15 percent (a much larger increase than will be examined in this paper). These findings are consistent with the substitution effect of taxes dominating - if the tax increases, work will decrease because its value has been lowered. However, this finding is not uniform. Gurley-Calvez and Hill (2011) find that increases in the state income tax actually decrease retirement, suggesting that at least with respect to state taxes the income effect may dominate and people may end up working longer to offset lower savings while employed.

\section{Model}

To examine the role of benefit cuts and tax increases in retirement and consumption, this paper follows the strand of the literature that utilized structural modeling. The structural model used in this paper is described in detail in Gustman and Steinmeier (2006), but a review of it with an eye on how Social Security benefit reductions and tax increases are ultimately incorporated is useful.

The model takes a lifecycle approach and focuses on the retirement behavior of men who begin their time in the Health and Retirement Study (HRS) as a part of a married couple. These individuals are assumed to maximize their expected lifetime utility subject to a budget constraint that incorporates income from labor, pensions and Social Security, and the returns from assets. Individuals face uncertainty over the rate of return on assets, their utility from continued work, and over their mortality. ${ }^{3}$ The paths of an individual's potential wages (realized if they work), health, and the formulation of the Social Security benefit are not stochastic and are assumed to be known by the individual. ${ }^{4}$ Given their constraints, workers are assumed to make choices about their labor supply and consumption. Lifetime utility is given by the following equation:

$$
E U_{i}=E_{i}\left[\sum_{t=a}^{T}\left\{e^{-\rho t} \sum_{m=1}^{3} s_{m, t}\left(\frac{1}{\alpha} C_{m, t}^{\alpha}+h_{t} L_{m, t}^{\gamma}\right)\right\}\right]
$$

\footnotetext{
${ }^{3}$ Individuals know their mortality rates but not when they will die.

${ }^{4}$ A later version of the model, Gustman and Steinmeier (2014), incorporated uncertainty in health and found that this addition did not change the model's overall conclusions. Gustman and Steinmeier (2015) incorporated uncertainty over the future of Social Security and found it did improve the models ability to fit retirement and claiming decisions.
} 
where the individual's marital status is indicated by $m$, which can be married with: 1) both spouses alive; 2) only the married man surviving; and 3) only the spouse surviving. ${ }^{5}$ The vector $s_{m, t}$ represents the likelihood of those situations arising by time $t$ and reflects mortality risk. The vector $h_{t}$ indicates the individual's leisure preference, which is allowed to vary as a function of his health and age. $L_{m, t}$, represents the labor/leisure decision, which can be working $\left(L_{m, t}=0\right)$, partially retired $\left(L_{m, t}=0.5\right)$, or fully retired $\left(L_{m, t}=1.0\right)$. The parameter $\gamma$ represents the individual's preference for partial retirement. ${ }^{6}$ Finally, the parameters $\rho$ and $\alpha$ capture an individual's time preference and the shape of the utility function regarding consumption, respectively. The vector $h_{t}$ is also where health enters the model. Specifically, the model specifies that the leisure term is:

$$
h_{t}=e^{\beta X_{t}+\varepsilon_{t}}
$$

where $X_{t}$ is a vector that contains a constant, the individual's age, and whether he is in poor health. ${ }^{7}$ The term $\varepsilon_{t}$ reflects the aforementioned uncertainty over the utility from leisure. ${ }^{8}$ A positive coefficient on poor health would indicate that it makes leisure more attractive than work.

Households make their leisure and consumption decisions under the following budget constraint:

$$
A_{t}=\left(1+r_{t}\right) A_{t-1}+W_{t}\left(1-L_{m, t}\right)+E_{m, t}+B_{m, t}-C_{m, t}
$$

where the assets available today (and ultimately in the future) depend on: 1 ) the assets available in the last period $\left(A_{t-1}\right)$, and the returns on those assets $\left.\left(r_{t}\right) ;{ }^{9} 2\right)$ wages $\left(W_{t}\right)$, which are allowed to be lower once an individual has quit the career job they entered the model with; 3 )

\footnotetext{
${ }^{5}$ The individual being modeled is assumed to not get any utility once they die, regardless of the spouse's survival status.

${ }^{6}$ The preference for partial retirement has an individual-specific component, $\delta$, and a "shifter" that potentially increases that preference with age, $\delta_{a}$.

${ }^{7}$ In the model, once people enter poor health they are assumed to remain in poor health.

${ }^{8}$ This uncertainty initially comes from a mean zero distribution and holds a single value until retirement from the career job. After retirement from this career job, $\varepsilon_{t}$, is allowed to vary over time, with a year-to-year correlation parameter of $\rho_{\varepsilon}$.

${ }^{9}$ The current paper uses returns calculated by Ibbotson Associates (2002) after taking into account the distribution of financial assets in the HRS, as in Gustman and Steinmeier (2006).
} 
income from the spouse, which includes both wage and pension income $\left(E_{m, t}\right) ;{ }^{10}$ and 4$)$ income from Social Security and from the individual's own pension $\left(B_{m, t}\right){ }^{11}$

Equations (1) through (3) paint an intuitive picture of how individuals make decisions about retirement and consumption within this model: they know that the choices they make today will alter their utility, level of income, and amount of assets both today and in the future. For example, deciding to work today brings some amount of disutility in the moment, but allows career wage income to continue, potentially increases the future Social Security benefit, and delays claiming one more year so that the benefit increases (if the individual is over the EEA). Individuals who continue working also know that they are able to continue accumulating assets and potentially pension wealth. So the decision affects utility today through the disutility from work and the availability of wage income and affects it tomorrow through the potential increase in Social Security wealth, pension wealth, and savings. When the disutility from work overcomes the current and future benefits, people retire.

Before discussing the data used to estimate this model, it is worth delving deeper into the two aspects of the model that will be changed in this paper to simulate policy, Social Security benefits and taxation.

\section{Social Security Benefits}

The modeling of Social Security benefits, contained in $B_{m, t}$ in equation (2), is straightforward. Given that the future potential income (if the individual works) from labor is known with certainty, the benefit from claiming Social Security at any age is also known in advance. Individuals are assumed to claim Social Security as soon as they retire. ${ }^{12}$ At this point, they receive their Primary Insurance Amount (PIA) reduced by any actuarial adjustment (or increased by the DRC) as determined by their birth cohort and the age at which they retired. ${ }^{13}$

\footnotetext{
${ }^{10}$ The spouse's wage income and pensions are treated as exogenous, as is her retirement decision.

${ }^{11}$ The Gustman and Steinmeier model includes both DB and DC plans. For DB pensions, the evolution of the benefit is determined by the individual's wages on his "career job" and by the rules of his pension plan. If those rules leave little to gain for working past certain ages or large gains from working to certain ages, they may have a large impact on retirement timing.

12 This assumption is based on evidence from Coile et al. (2002) that people typically claim Social Security as soon as possible, although a later version of the Gustman and Steinmeier model allows claiming to be investigated separately.

${ }^{13}$ Because the spouse's income is treated as exogenous, their claiming decision is not modeled, but the size of the household benefit does depend on whether both members are alive and on the lifetime earnings and subsequent benefit size of the spouse.
} 
These assumptions mean that Social Security benefits in the model tend to keep people in the workforce until age 62, and that delaying retirement has the benefit of increasing post-retirement income. Increasing the FRA or decreasing the COLA can be incorporated by altering the benefit formula.

\section{Payroll Taxation}

Taxes are not explicitly included in the Gustman and Steinmeier (2006) model (i.e., the budget constraint is assumed to reflect post-tax wages, assets, and consumption). To simulate changes in the payroll tax, the income from work will be reduced by the appropriate amount given the rate assumed and the assumed cap.

\section{Data and Estimation}

This section first describes the data gathered to estimate the model described above and then describes the estimation process.

\section{Data}

The data come from the original HRS Cohort waves 1 through 6, as was used in Gustman and Steinmeier (2006). As in Gustman and Steinmeier (2006), the sample begins with married men and then eliminates individuals by introducing a number of restrictions, as listed in Table 1 . Table 1 indicates that these restrictions reduce the sample from just over 12,000 individuals to about 2,200. The most important restrictions are that individuals with retirement plans but without data on those pensions are dropped as are individuals with unstable employment histories. ${ }^{14}$

Perhaps the most important individual variable for estimation of the model is labor participation status. In the data, individuals working at least 30 hours each week and 1,560 hours a year are counted as full-time workers; between 100 hours and 1,250 hours a year and 25 hours or less per week are labeled as part-time and partially retired; and individuals working less than 100 hours per year are fully retired. The paper focuses on the time at which people completely retire from work, and Figure 1 shows how the share of workers who are completely retired

\footnotetext{
${ }^{14}$ The justification for these restrictions is discussed at length in Gustman and Steinmeier (2006).
} 
changes with age. The most notable feature of the data is the large increase in the share completely retired at the Early Eligibility Age of 62.

Data for the budget constraint (equation (3)) come from a variety of sources. For HRS sample members who are linked to Social Security earnings records, these records are used to determine their labor income. For the roughly quarter of respondents remaining, earnings histories are constructed from self-reported earnings on the current job or any previous job lasting more than five years. Because behavior is modeled for most individuals beyond their time in the data - not all HRS Cohort members were 69 years old in 2004 when the data end earnings must be projected into the future. This projection follows Gustman and Steinmeier (2006), using a regression on an individual's experience and tenure to form predictions. The individual's Social Security PIA needed to determine his benefit is calculated based on his earnings history and is updated each year that he works. His benefit is determined by the rules when he claims, which (as mentioned above) occurs at the same time that he retires.

Information on defined benefit (DB) pensions comes from summary plan descriptions provided by the individual's employer. For defined contribution (DC) plans, account balances are updated year by year based on the individual's earnings and contribution rates and the employer's contribution rate. The assets in the DC account are assumed to grow at the same stochastic rate of return as any other assets. The final source of data needed to complete equation (3) is any wage, pension, or Social Security income from spouses. Generally, these quantities are calculated in the same way as they are for men, with the exception that they are treated as exogenous (unlike the man's earnings, which can be affected by the decision to work).

Aside from the resource constraint, information on an individual's health is also required to determine the utility from continued work as modeled by equation (2). A person's health is treated as a binary variable equal to 1 if the individual self-reports being in poor health and 0 otherwise. Once an individual is in poor health, he is assumed to stay in poor health for the remainder of his time in the model.

\section{Estimation}

The goal of estimating the model is to obtain the preference parameters in equations (1) and (2). Once these quantities are estimated, the model can be used to simulate individual behavior and ultimately conduct the four policy experiments laid out in the introduction. The 
parameters include the consumption parameter from equation (1); the distribution of individual preferences for partial retirement also from equation (1); the distribution and year-to-year correlation of uncertainty in a person's leisure preference from equation (2); and the effect of age and health on the preference for leisure, also from equation (2).

As is standard in dynamic stochastic structural models like that used in this paper, the model is solved recursively and then estimated iteratively. For a given set of parameters, the model is solved by starting in the final modeled year, $T$, and determining how the individual would behave at this time for any combination of earnings, assets, and career versus non-career job they could arrive at that time with. Because it is the final period of the model, the individual does not need to consider the future and so his decision is relatively easy - he consumes everything and works if the extra income more than balances out the disutility of labor.

At the period T-1, the decision becomes harder because a future period must be incorporated into the individual's decision. Again, for a given set of parameters, the current utilities are calculated at each possible model outcome. Although one choice will yield the highest utility at time $\mathrm{T}-1$, the individual must also consider that the choice impacts the assets available tomorrow and thus his expected utility in the future. Fortunately, given the individual is assumed to know the distribution of the rate of return, he can calculate the probability that he will end up at any particular asset level tomorrow given his choice of consumption today. And because he has solved the model already at time $\mathrm{T}$ at each asset level, he can determine his expected utility from work given he knows the distribution of uncertainty in his preference for leisure. This knowledge allows individuals to make a labor and consumption choice today that maximizes not just their utility today, but their expected utility in the future periods. Work and consumption decisions are modeled in this way going back to the first period of the model.

Once this iterative process is complete all the way back to age 51, each individual will have a simulated work history. The goal of the estimation routine is to closely match these work histories to reality. To accomplish this goal, the model uses the Generalized Method of Moments (GMM). The GMM methodology is relatively straightforward and compares moments from the actual data to the same moments from the simulated data. One example of such a moment is the share of people in poor health at any given age who have completely retired. If the parameters generated by the model are close to the true parameters, then the difference between the simulated and actual moments will be small. The estimation process proceeds 
iteratively - if the model predicts that people who are sick work far more often than they actually do, then the next time the parameters are guessed will reflect a larger penalty for working while in poor health. In this iterative way, the model arrives at parameters for which the model fits the chosen moments. ${ }^{15}$

\section{Results}

Before discussing the results of the policy simulations, it is useful to do two preliminary exercises to ensure the simulations are meaningful. The first exercise is to "internally validate" the model by showing that it at least fits the data on which it was estimated. Given that policy simulations are, by definition, "out of sample" exercises, it is important that the model at least yields good “in sample” predictions. On this point, the Gustman and Steinmeier (2006) model performs fairly well with respect to the main behavioral outcome of interest in this study: complete retirement. Figure 2 shows that, up until age 65, the predicted shares completely retired trend very closely to the actual share. After age 65, the model slightly under-predicts the share of people completely retired.

The second exercise is to "externally validate" the model. Because the goal of this paper is to predict how people are likely to respond to policy changes that have not yet occurred, it is useful to know if the model can accurately predict their responses to changes that occurred between the time the model was estimated and today. An analysis in Hou et al. (2017) using the Gustman and Steinmeier (2006) model yields an encouraging result. In that paper, the authors looked at how much of the change in behavior between the HRS Cohort and the Early Baby Boomer Cohort (born roughly 12 years later) could be explained by four major changes that played out over that time: 1) changes in Social Security rules; 2) changes in pension structure; 3) improvements in health; and 4) improvements in mortality. To accomplish this comparison, the authors re-simulated the model and replaced the actual characteristics of the HRS Cohort along those four dimensions with simulated characteristics based on the Early Baby Boomer Cohort. For example, many workers in the original HRS Cohort with DB pensions were assigned DC

\footnotetext{
${ }^{15}$ Results can be found in the Appendix. More details are provided in Gustman and Steinmeier (2006), including on how the iterative process is carried out and how the fit of the model to the moments is evaluated. The moments used include the share fully retired at all ages 54 to 66 ; the share partially retired at ages 55, 58, 60, 62, and 65; the share fully retired in the upper and lower thirds of lifetime income at ages 55, 58, 60, 62, and 65; the share fully or partially retired who are in poor health at ages $55,58,60,62$, and 65 ; and the frequency with which individuals return to full-time work given that they were fully or partially retired. All in all, there are 43 moments.
} 
pensions with the same pension wealth, but without the retirement rules that correspond to DB plans. Although these four changes do not represent all changes in the economy over those four years, one would expect they explain a good portion of any change in behavior. Figure 3 suggests that these changes do explain much of the decrease in retirement seen between the two cohorts, which bodes well for the accuracy of the counterfactual predictions discussed below.

\section{Reductions in Benefits}

The simulations begin with today’s “baseline” policy - an FRA of 67, a DRC between 67 and 70, and the elimination of the earnings test over age $67 .{ }^{16}$ To simulate the FRA increasing to 69 , the benefit reduction of retiring prior to 67 was increased to reflect two additional years, a reduction consistent with two years of early claiming was incorporated at 67 , a reduction consistent with one year of early claiming was incorporated at 68, and only one year of a DRC was allowed. To simulate the effect of a 0.5-percent COLA reduction, the individual's real benefit was divided by $1.005^{(\mathrm{a}-\mathrm{c})}$ where $a$ is his current age and $c$ is the age at which he claimed. This means that, in this simulation, delaying retirement has a small side benefit - it delays the time in which the benefit begins being deflated.

The results of the experiments are shown in Table 2. The effect of increasing the FRA from 67 to 69 is similar in magnitude to the effect of increasing it to 67 found in Gustman and Steinmeier (2006). Between the ages of 62 and 69, the reduction can be as small as 0.8 percent or as large as 4.4 percent. And like Gustman and Steinmeier (2006), the effect on retirement is “u-shaped” - i.e., with larger decreases around 62 followed by a smaller effect in the mid-60s and then larger decreases again. The reason for this shape stems from the increase in the FRA both reducing benefits and reducing the gains to delayed retirement - at various ages these effects offset each other differently. The effect of the COLA decrease is generally smaller, but also more consistent over the age range than the FRA increase, with decreases of between 2.0 and 2.5 percent in the share completely retired between ages 62 and 69. In general, it seems either policy would delay retirement for the average worker. It is worth noting that these behavioral effects are slightly larger for low-income individuals (see Table 3). For example, for the FRA increase, the reduction in the share completely retired at ages 62-69 for individuals in

\footnotetext{
${ }^{16}$ This "baseline" policy is not the original policy from the Gustman and Steinmeier model, which used the Social Security policy relevant for each individual given their birth cohort. However, since the policy changes being discussed build off today's policy, a slightly different approach is needed.
} 
the bottom third of the income distribution ranges from 4.2 percent to 7.5 percent and for individuals in the top third from an increase of 1.7 percent to a decrease of 2.4 percent. The pattern is again u-shaped across the income groups. While the small increase in the mid-60s for the middle- and high-income groups is somewhat counterintuitive, Gustman and Steinmeier (2006) found a similar increase even for the average worker (see the literature review for a discussion). Intuitively, the fact that low-income workers see a larger decrease in retirement than high-income workers makes sense since low-income individuals are generally more reliant on Social Security for consumption, a topic which the paper turns to next.

Figure 4 shows the percentage reduction in consumption during the working years and then in retirement by income tercile for an increase in the FRA and Figure 5 for a decrease in the COLA. Both policies reduce consumption slightly prior to retirement as workers approach the EEA and the need to save more to offset benefit reductions becomes less distant and so less discounted. However, the size of the consumption reduction during retirement differs considerably across the two policies. Increasing the FRA to 69 results in a larger decline in consumption early in the retirement period, while the COLA results in a larger reduction later in retirement. For example, Figure 4 shows that - for low-income individuals - the reduction in consumption at age 65 is about 2.0 percent under an FRA of 69 and 0.7 percent under the COLA reduction. At age 90, those relative magnitudes are reversed to 7.2 percent and 10.5 percent, since the COLA reduction results in a larger decrease in benefits with age. ${ }^{17}$ Both policies result in a larger percentage reduction in consumption for lower-income individuals than higherincome individuals, who are less reliant on Social Security.

\section{Increase in Taxes}

Table 4 shows the share completely retired under the two tax increase policies and indicates essentially no effect on retirement timing. This result contrasts with Van der Klauuw and Wolpin (2008), who found a larger effect, although they also looked at a much larger tax increase. In any case, neither increasing the payroll tax to 7.75 percent nor raising the cap is expected to have a large effect on retirement timing according to the Gustman and Steinmeier

\footnotetext{
17 The effect of both policies increases with age as individuals spend down their other wealth and rely more and more on Social Security income.
} 
model. With respect to changes in the timing of retirement, little difference exists between the income groups.

The effect on consumption of a payroll tax increase is shown in Figure 6. For simplicity, only the average decline is shown since the reduction is similar across income groups (if slightly smaller for high-income individuals who rely less on labor income during their working lives). The main takeaway is that an increase in the payroll tax from 6.2 percent to 7.75 percent has the predictable effect of decreasing consumption during the working life by about 1.5 percent, with the effect dissipating as people retire and cease relying on wage earnings. Still, a small residual effect remains even once all workers are assumed retired, since less was saved while they were working. Finally, Figure 7 shows the reduction in consumption under a payroll-cap increase for individuals in the highest income tercile (the only ones affected by such a policy in the model). The result shows a similar, but muted, pattern to the payroll tax increase. ${ }^{18}$

\section{The Effect of Policies in Today's Pension and Health Environment}

One thing worth noting about the model used here is that the characteristics of individuals included are those of the original HRS cohort (as discussed above). A logical question is whether the behavioral effects will differ greatly in today's world, when workers are more likely to rely on DC pensions and remain in better health longer. After all, Hou et al. (2017) found that increases in DC coverage and improvements in health explained a large portion of the reduction in retirement seen by the Early Boomer cohort relative to the original HRS cohort. To examine this issue, the paper assigned health and pension characteristics consistent with the Early Boomer cohort to members of the model's sample and examined how they would respond to an increase in the FRA to 69 (the policy change with the largest behavioral effect).

The results are shown in Table 5 and suggest a slight magnification of the behavioral effect. In the original policy experiment, the effect of an increase in the FRA to 69 ranged from a reduction in the share completely retired of 0.3 percent to 4.4 percent. With improved health and a higher share of pensions as DCs, the increase in the FRA is predicted to result in a

\footnotetext{
${ }^{18}$ In Gustman and Steinmeier's model, the sample used HRS data from 1992-2002, which closely tracks the historical values of the ratio of taxable payroll to covered earnings. However, the 2015 Technical Panel on Assumptions and Methods recommends lowering the ultimate level of the taxable share to 82.2 percent in the longterm, which is much lower than the values during 1992 to 2002 (See Figure 31 in the technical panel report). This difference means the effect on consumption of an increase in the cap will be smaller in this analysis than in reality.
} 
reduction in the share completely retired of 0.7 percent to 5.7 percent. Although the effects that incorporate improved health and a greater share of DC pensions are slightly larger than the effects under the original experiment, the model seems to suggest that the health and pension changes will not greatly exaggerate the effect of benefit reductions on behavior.

\section{Conclusion}

As policymakers consider ways to address Social Security's financial shortfall, a variety of policy changes are possible that could have similar effects on the program's finances. This paper shows the differing effects on recipients of some of those policies. The results suggest that benefit reductions tend to have a larger behavioral effect than tax increases, likely because the decrease in retirement income is larger - albeit concentrated over a smaller time period. The reduction in consumption under benefit reductions is substantially larger during retirement than under a payroll tax or cap increase, but the latter policies decrease consumption more during the working lives of individuals, which are considerably longer than retirement. Therefore, this research suggests that one tradeoff policymakers face is between a long period of lower consumption pre-retirement and a shorter, but more pronounced period, of lower consumption post-retirement. 


\section{References}

Alpert, Abby and David Powell. 2012. “Tax Elasticity of Labor Earnings for Older Individuals.” Working Paper 2012-272. Ann Arbor, MI: Michigan Retirement Research Center.

Blau, David M. and Ryan M. Goodstein. 2010. “Can Social Security Explain Trends in Labor Force Participation of Older Men in the United States?” Journal of Human Resources 45(2): 328-363.

Burtless, Gary. 1986. "Social Security, Unanticipated Benefit Increases, and the Timing of Retirement.” 1986. Review of Economic Studies 53(5): 781-805.

Coile, Courtney, Peter Diamond, Jonathan Gruber, and Alain Jousten. 2002. "Delays in Claiming Social Security Benefits.” Journal of Public Economics 84(3): 357-385.

Gurley-Calvez, Tami and Brian Hill. 2011. "Time to Retire? The Effect of State Fiscal Policies on Retirement Decisions.” American Economic Review: Papers \& Proceedings 101(3): 35-39.

Gustman, Alan L. and Thomas L. Steinmeier. 2006. “Social Security and Retirement Dynamics.” Working Paper 2006-121. Ann Arbor, MI: Michigan Retirement Research Center.

Gustman, Alan L. and Thomas Steinmeier. 2009. "How Changes in Social Security Affect Recent Retirement Trends.” Research on Aging 31(2): 261-290.

Gustman, Alan L. and Thomas Steinmeier. 2015. "Effects of Social Security Policies on Benefit Claiming, Retirement, and Saving.” Journal of Public Economics 129(9): 51-62.

Hou, Wenliang, Alicia H. Munnell, Geoffrey T. Sanzenbacher, and Yinji Li. 2017. "Why Are U.S. Households Claiming Social Security Later?” Working Paper 2017-3. Chestnut Hill, MA: Center for Retirement Research at Boston College.

Mastrobuoni, Giovanni. 2009. "Labor Supply Effects of the Recent Social Security Benefit Cuts: Empirical Estimates Using Cohort Discontinuities.” Journal of Public Economics 93(11): 1224-1233.

Schmidt, Lucie and Purvi Sevak. 2009. “Taxes, Wages, and the Labor Supply of Older Americans.” Research on Aging 31(2): 207-232.

Van der Klaauw, Wilbert and Kenneth I. Wolpin. 2008. "Social Security and the Retirement and Saving Behavior of Low-Income Households.” Journal of Econometrics 145(1): 21-42. 
Figure 1. Share of Sample Completely Retired, Ages 50-69

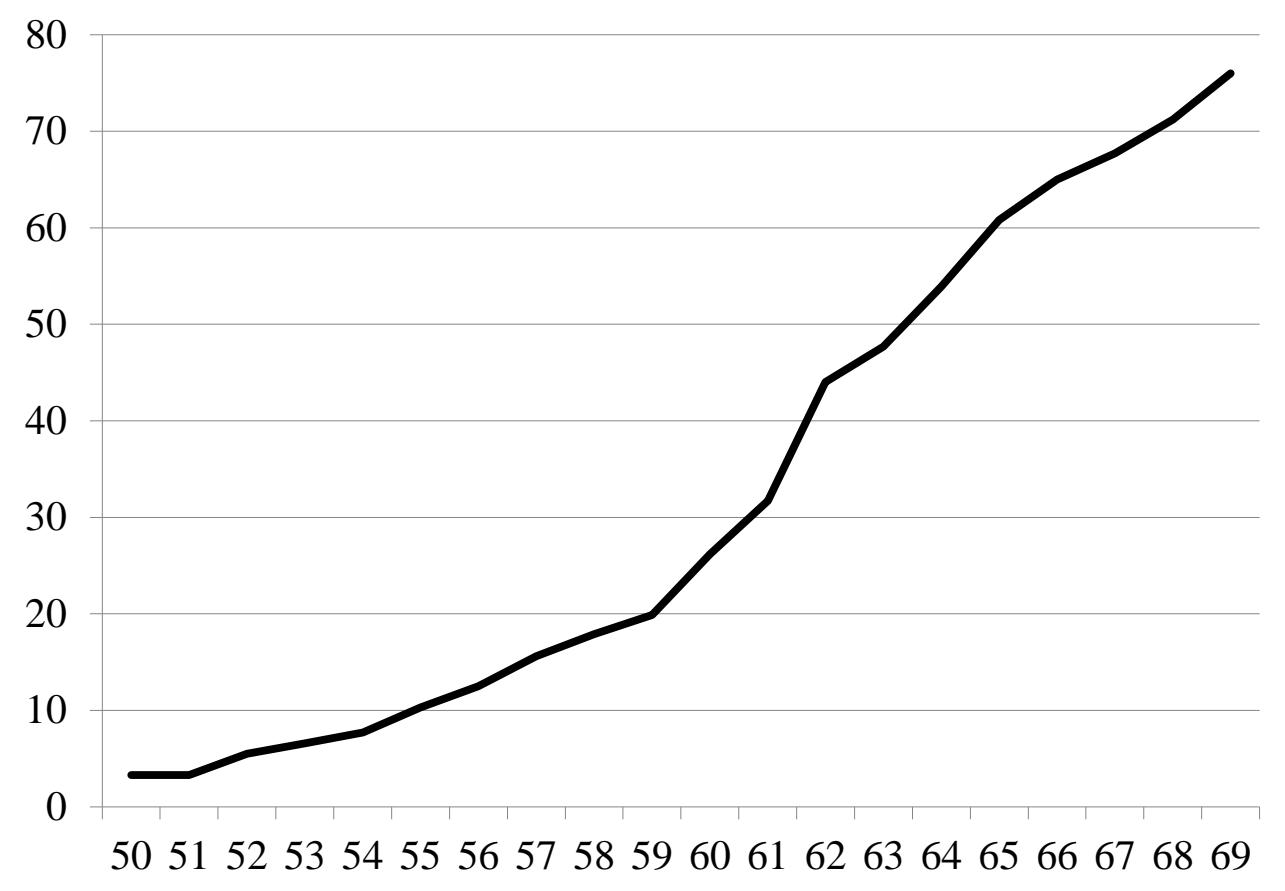

Sources: Authors' calculations from the Health and Retirement Study and Gustman and Steinmeier (2006).

Figure 2. Actual and Predicted Share Completely Retired, Ages 50-69

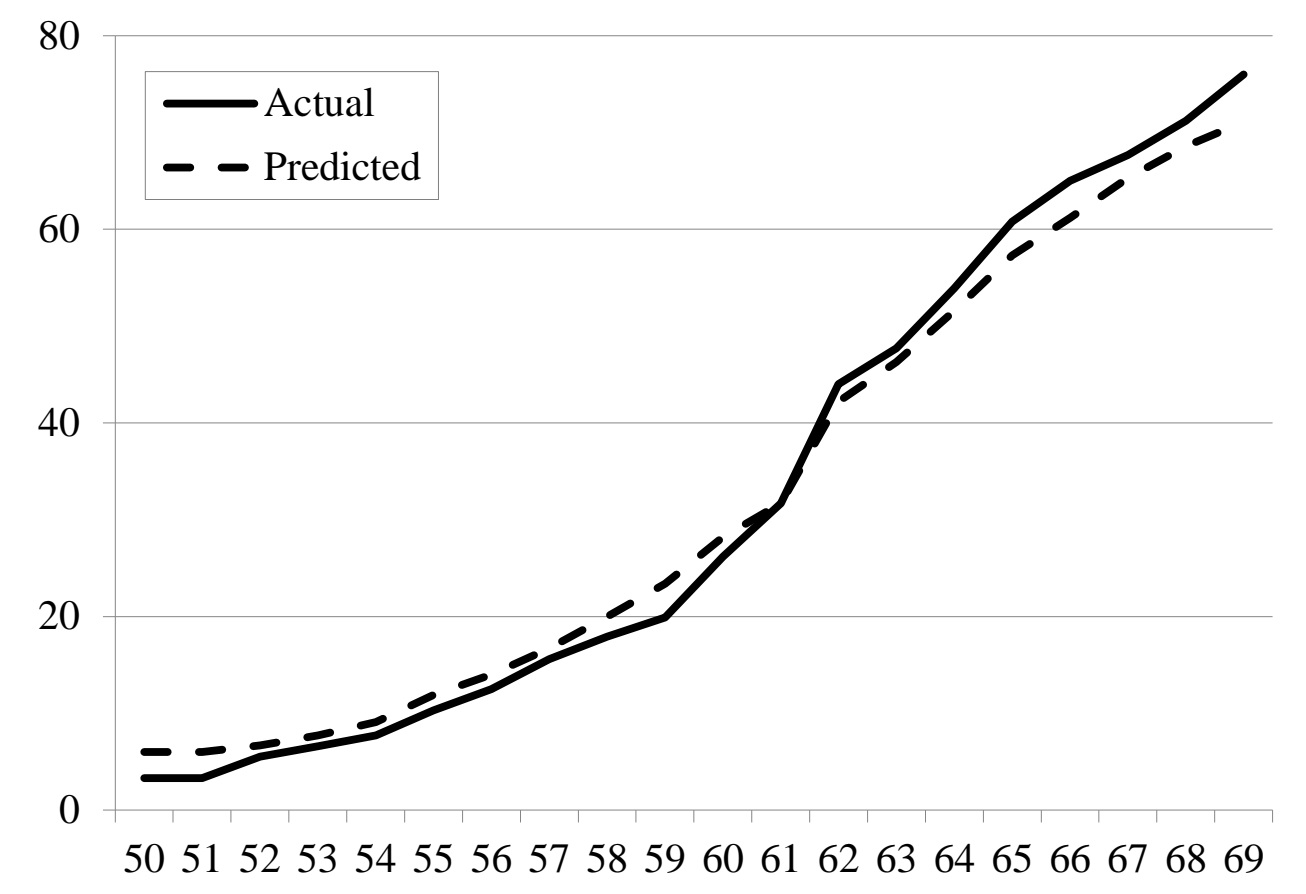

Sources: Authors' calculations from the Health and Retirement Study and Gustman and Steinmeier (2006). 
Figure 3. Share of Sample Completely Retired, Ages 50-69, by Cohort



5051525354555657585960616263646566676869

Sources: Authors' calculations from the Health and Retirement Study and Gustman and Steinmeier (2006).

Figure 4. Percentage Reduction in Consumption under FRA Increase, Ages 25-90, by Income Tercile



Sources: Authors' calculations from the Health and Retirement Study and Gustman and Steinmeier (2006). 
Figure 5. Percentage Reduction in Consumption under COLA Decrease, Ages 25-90, by Income Tercile

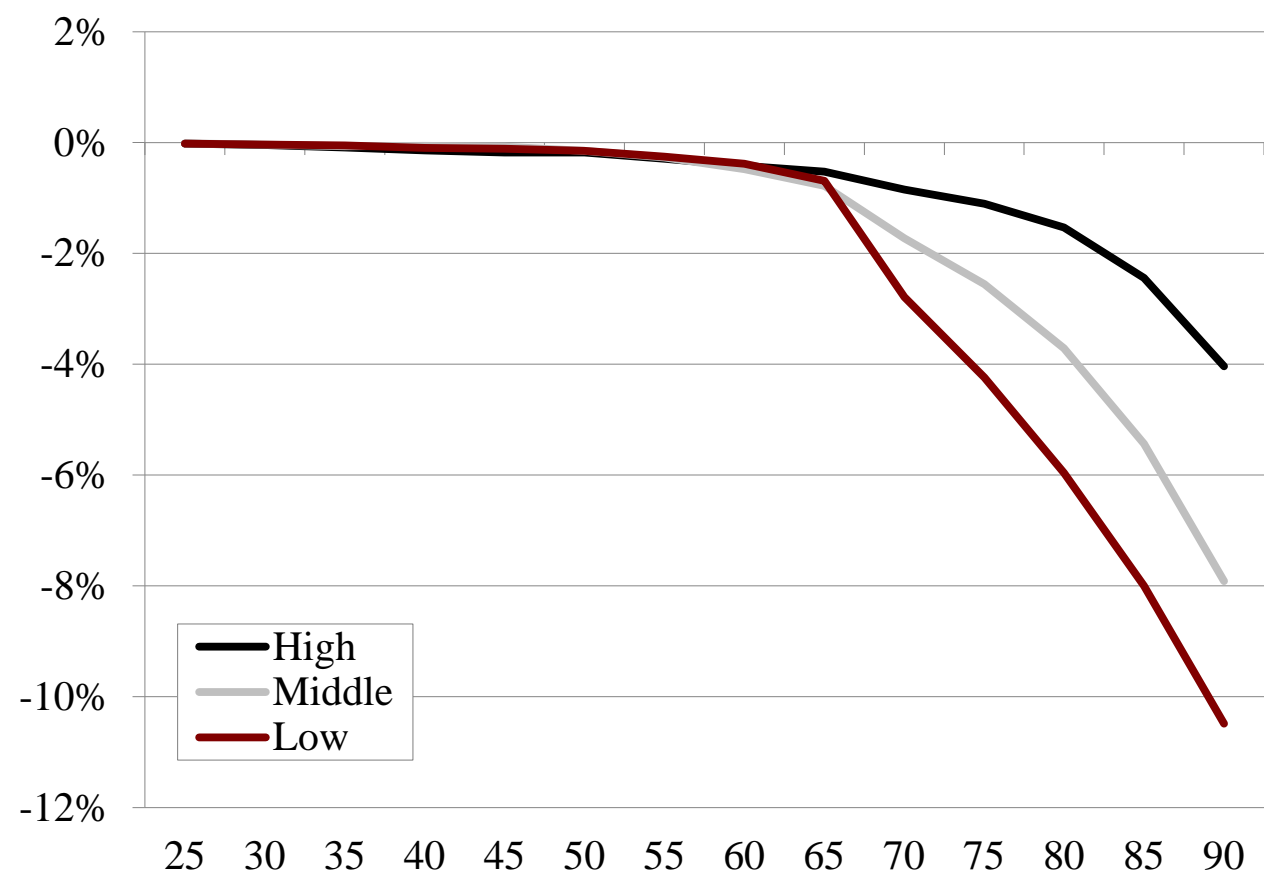

Sources: Authors' calculations from the Health and Retirement Study and Gustman and Steinmeier (2006).

Figure 6. Average Percentage Reduction in Consumption under Payroll Tax Increase, Ages 2590

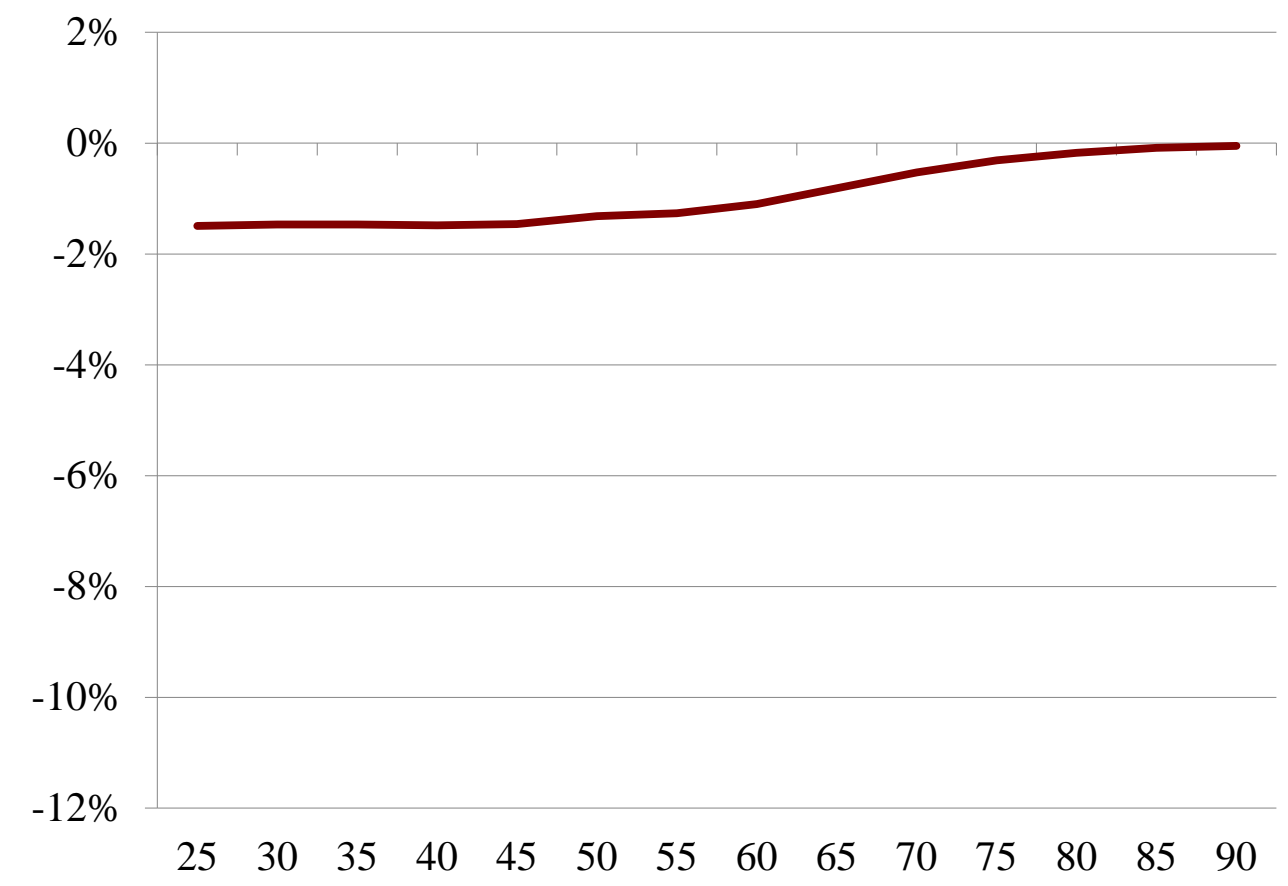

Sources: Authors’ calculations from the Health and Retirement Study and Gustman and Steinmeier (2006). 
Figure 7. Average Percentage Reduction in Consumption under Payroll Cap Increase, Ages 2590, Highest Income Tercile

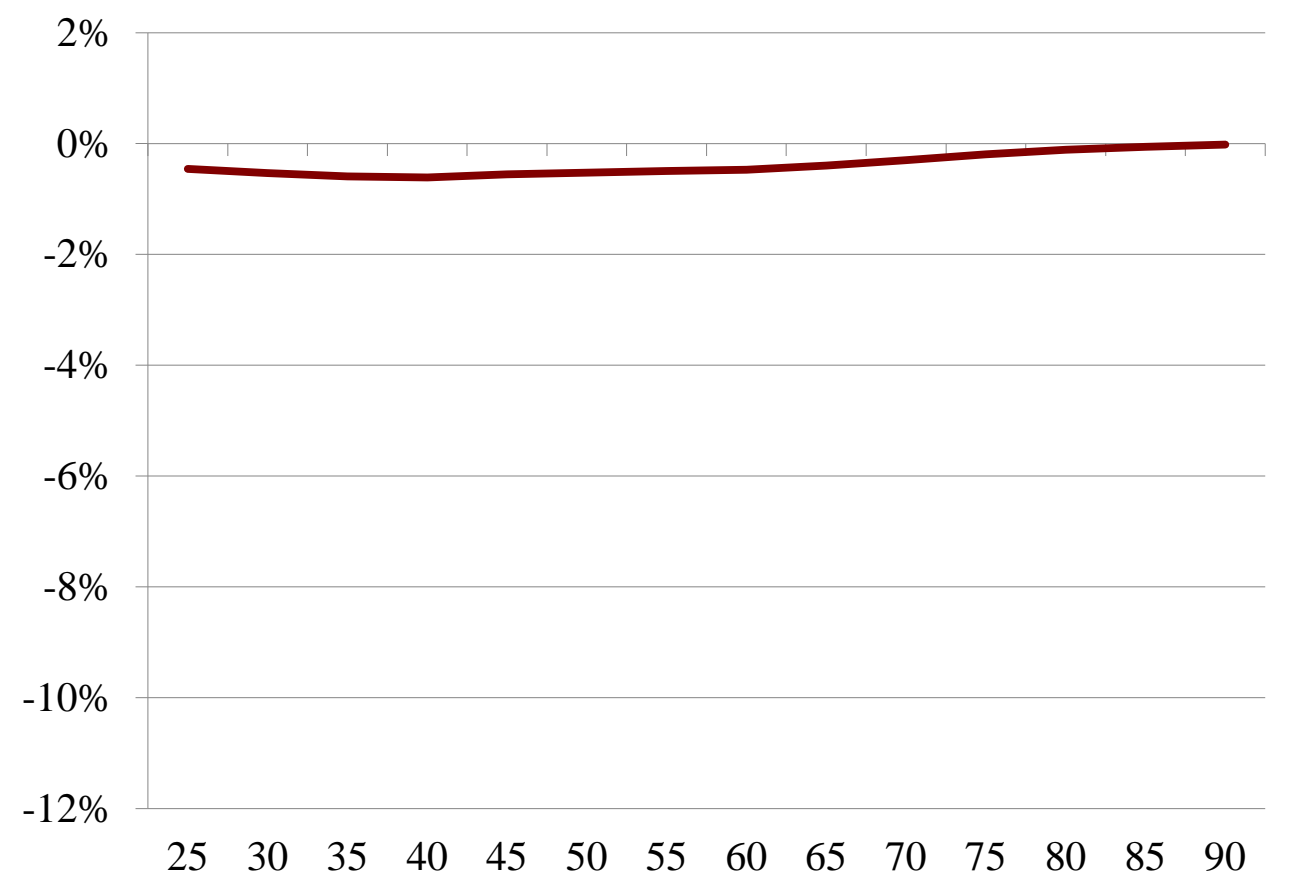

Sources: Authors' calculations from the Health and Retirement Study and Gustman and Steinmeier (2006). 
Table 1. Sample Size Following Restrictions Imposed by Gustman and Steinmeier (2006)

\begin{tabular}{|c|c|c|}
\hline \multirow[b]{2}{*}{ Restriction criteria } & \multicolumn{2}{|c|}{ HRS cohort } \\
\hline & Observations dropped & Observations left \\
\hline Total sample of individuals & & 12,652 \\
\hline Men married at first sampled wave & 6,785 & 5,867 \\
\hline Divorced or widowed after age 35 & 1,578 & 4,289 \\
\hline Spouse not interviewed in first wave & 133 & 4,156 \\
\hline Respondent does not have career job & 497 & 3,659 \\
\hline Ambiguity about Social Security coverage & 49 & 3,610 \\
\hline No full-time earnings & 36 & 3,574 \\
\hline $\begin{array}{l}\text { No self-reported earnings, Social Security } \\
\text { earnings over limit }\end{array}$ & 31 & 3,543 \\
\hline Relatively large business assets & 291 & 3,252 \\
\hline No pension provider record in last job & 865 & 2,387 \\
\hline Fulltime years of work unavailable for spouse & 156 & 2,231 \\
\hline
\end{tabular}

Sources: Authors' calculations from the Health and Retirement Study and Gustman and Steinmeier (2006).

Table 2. Share Completely Retired Under Policies to Reduce Benefits

\begin{tabular}{llllllc}
\hline & \multicolumn{3}{c}{ Share completely retired } & & \multicolumn{2}{c}{ Percentage change from baseline } \\
\cline { 2 - 4 } Age & Baseline & FRA 69 & COLA reduction nn & & FRA 69 & COLA reduction \\
\hline 62 & $42.6 \%$ & $40.8 \%$ & $41.7 \%$ & & $-4.2 \%$ & $-2.0 \%$ \\
63 & 46.8 & 45.0 & 45.9 & & -3.9 & -2.1 \\
64 & 49.8 & 49.7 & 48.8 & & -0.3 & -2.0 \\
65 & 55.0 & 54.5 & 53.8 & & -0.8 & -2.0 \\
66 & 59.5 & 56.9 & 58.3 & & -4.4 & -2.1 \\
67 & 63.0 & 61.5 & 61.4 & & -2.3 & -2.5 \\
68 & 66.6 & 65.3 & 65.0 & & -2.0 & -2.4 \\
69 & 69.2 & 66.5 & 67.5 & & -3.9 & -2.4 \\
\hline
\end{tabular}

Sources: Authors' calculations from the Health and Retirement Study and Gustman and Steinmeier (2006). 
Table 3. Percentage Change from Baseline in Share Completely Retired under Policies to Reduce Benefits, by Income Tercile

\begin{tabular}{llllllll}
\hline & \multicolumn{3}{c}{ FRA 69 } & & \multicolumn{3}{c}{ COLA reduction } \\
\cline { 2 - 5 } \cline { 6 - 8 } Age & Low & Middle & High & & Low & Middle & High \\
\hline 62 & $-7.1 \%$ & $-4.1 \%$ & $-2.4 \%$ & & $-3.4 \%$ & $-2.2 \%$ & $-1.0 \%$ \\
63 & -6.4 & -3.7 & -2.3 & & -3.5 & -2.2 & -1.1 \\
64 & -4.2 & 0.7 & 1.7 & & -3.5 & -2.0 & -0.9 \\
65 & -4.5 & 0.1 & 1.2 & & -3.5 & -2.1 & -0.9 \\
66 & -7.0 & -4.3 & -2.4 & & -3.5 & -2.2 & -1.0 \\
67 & -5.0 & -1.7 & -0.9 & & -3.5 & -2.6 & -1.5 \\
68 & -4.8 & -1.4 & -0.3 & & -3.4 & -2.5 & -1.5 \\
69 & -5.5 & -4.1 & -2.4 & & -3.4 & -2.5 & -1.5 \\
\hline
\end{tabular}

Sources: Authors' calculations from the HRS and Gustman and Steinmeier (2006).

Table 4. Percentage Change from Baseline in Share Completely Retired under Policies to Increase Revenues, by Income Tercile

\begin{tabular}{lcccccc}
\hline & \multicolumn{3}{c}{ Share completely retired } & & \multicolumn{2}{c}{ Percentage change from baseline } \\
\cline { 2 - 3 } Age & Baseline & $\begin{array}{c}\text { Payroll tax } \\
\text { increase }\end{array}$ & $\begin{array}{c}\text { Payroll cap } \\
\text { increase }\end{array}$ & $\begin{array}{c}\text { Payroll tax } \\
\text { increase }\end{array}$ & $\begin{array}{c}\text { Payroll cap } \\
\text { increase }\end{array}$ \\
\hline 62 & $42.6 \%$ & $42.6 \%$ & $42.6 \%$ & & $0.1 \%$ & $<0.1 \%$ \\
63 & 46.8 & 46.9 & 46.8 & & 0.1 & $<0.1$ \\
64 & 49.8 & 49.9 & 49.8 & 0.2 & $<0.1$ \\
65 & 55.0 & 55.1 & 55.0 & & 0.2 & $<0.1$ \\
66 & 59.5 & 59.7 & 59.5 & & 0.2 & $<0.1$ \\
67 & 63.0 & 63.2 & 63.0 & & 0.3 & $<0.1$ \\
68 & 66.6 & 66.8 & 66.6 & & 0.3 & $<0.1$ \\
69 & 69.2 & 69.3 & 69.2 & & 0.3 & $<0.1$ \\
\hline
\end{tabular}

Sources: Authors' calculations from the HRS and Gustman and Steinmeier (2006). 
Table 5. Share Completely Retired given Pension and Health Characteristics of Early Boomer Cohort

\begin{tabular}{llcc}
\hline Age & Baseline & FRA 69 & Percentage change \\
\hline 62 & $39.2 \%$ & $37.4 \%$ & $-4.5 \%$ \\
63 & 42.8 & 40.9 & -4.4 \\
64 & 45.3 & 45.0 & -0.7 \\
65 & 49.8 & 49.0 & -1.5 \\
66 & 54.5 & 51.4 & -5.7 \\
67 & 57.4 & 56.0 & -2.5 \\
68 & 61.2 & 59.8 & -2.3 \\
69 & 63.7 & 60.5 & -5.2 \\
\hline
\end{tabular}

Sources: Authors' calculations from the Health and Retirement Study and Gustman and Steinmeier (2006). 


\section{Appendix}

Table A1. Parameter Estimates

\begin{tabular}{llcr}
\hline Symbol & Description & Coefficient value & t-statistic \\
\hline$\alpha$ & Consumption parameter & -0.24 & 2.36 \\
& Parameters in $\beta$ & & \\
$\beta 0$ & Constant & -9.82 & 51.46 \\
$\beta \mathrm{a}$ & Coefficient of age & 0.659 & 3.68 \\
$\beta \mathrm{h}$ & Coefficient of health & 6.78 & 7.82 \\
$\rho \varepsilon$ & Correlation of $\varepsilon$ after retirement & 0.88 & 38.54 \\
& Parameters in $\delta$ & -5.34 & 2.12 \\
$\delta 0$ & Constant & -0.48 & 1.14 \\
$\delta \mathrm{a}$ & Coefficient of Ageb q value: & 5.40 & 25.58 \\
$\sigma \varepsilon$ & Standard deviation of $\varepsilon$ & 53.32 \\
\hline \multicolumn{4}{c}{ Number of observations: } \\
\hline
\end{tabular}

Sources: Authors' calculations from the Health and Retirement Study and Gustman and Steinmeier (2006). 


\section{RECENT WORKING PAPERS FROM THE CENTER FOR RETIREMENT RESEARCH AT BOSTON COLLEGE}

Family Transfers With Retirement-Aged Adults in the United States: Kin Availability, Wealth Differentials, Geographic Proximity, Gender, and Racial Disparities

Ashton M. Verdery, Jonathan Daw, Colin Campbell, and Rachel Margolis, August 2017

Guardianship and the Representative Payee Program

Anek Belbase and Geoffrey T. Sanzenbacher, August 2017

The Relative Effects of Economic and Non-Economic Factors on Taxpayers' Preferences Between Front-Loaded and Back-Loaded Retirement Savings Plans

Andrew D. Cuccia, Marcus M. Doxey, and Shane R. Stinson, July 2017

Social Security and Total Replacement Rates in Disability and Retirement

Mashfiqur R. Khan, Matthew S. Rutledge, and Geoffrey T. Sanzenbacher, May 2017

An Experimental Analysis of Modifications to the Survivor Benefit Information within the Social Security Statement

Jeffrey Diebold and Susan Camilleri, May 2017

Actuarial Inputs and the Valuation of Public Pension Liabilities and Contribution Requirements: A Simulation Approach

Gang Chen and David S. T. Matkin, May 2017

Why Are U.S. Households Claiming Social Security Later?

Wenliang Hou, Alicia H. Munnell, Geoffrey T. Sanzenbacher, and Yinji Li, April 2017

Rising Inequality in Life Expectancy by Socioeconomic Status

Geoffrey T. Sanzenbacher, Anthony Webb, Candace M. Cosgrove, and Natalia S. Orlova, April 2017

The Effect of Job Mobility on Retirement Timing by Education

Geoffrey T. Sanzenbacher, Steven A. Sass, and Christopher M. Gillis, February 2017

Would Reducing the Price of Employing an Older Worker Improve Labor Market Outcomes by Socioeconomic Status? Evidence from Health Insurance Premium Restrictions

Matthew S. Rutledge and Caroline V. Crawford, December 2016

All working papers are available on the Center for Retirement Research website (http://crr.bc.edu) and can be requested by e-mail (crr@bc.edu) or phone (617-552-1762). 